\title{
Влияние тиотропия бромида на переносимость физической нагрузки и качество жизни у больных хронической обструктивной болезнью легких
}

1 - кафедра внутренних болезней педиатрического факультета ГОУ ВПО "Сибирский государственный медицинский университет": 634050, Томск, Московский тракт, 2;

2 - МКЛПМУ "Городская больница № 3": 634034, Томск, ул. Нахимова, 3

\section{L.I.Volkova, A.V.Timofeeva, E.S.Smolina, Z.R.Aminova \\ Effects of tiotropium bromide on physical tolerance and quality of life in patients with chronic obstructive pulmonary disease}

\begin{abstract}
Summary
Six-minute walking distance as a measure of physical tolerance and quality of life were studied in 37 patients with chronic obstructive pulmonary disease (COPD) receiving tiotropium bromide for 1 year. Before this study, these patients had not been treated with this drug. The long-term therapy with tiotropium bromide was found to improve physical tolerance and quality of life in all stages of COPD.

Key words: chronic obstructive pulmonary disease, tiotropium bromide, 6-minute walking test, quality of life.
\end{abstract}

\section{Резюме}

Изучены динамика 6-минутного шагового теста, отражающего толерантность к физической нагрузке, и качество жизни у 37 больных хронической обструктивной болезнью легких (ХОБЛ) при терапии тиотропия бромидом в течение 1 года, при условии, что этот препарат был назначен впервые. Установлено, что длительная терапия тиотропия бромидом позволяет улучшить переносимость физических нагрузок и качество жизни у пациентов с любой стадией ХОБЛ.

Ключевые слова: хроническая обструктивная болезнь легких, тиотропия бромид, 6-минутный шаговый тест, качество жизни.

Наиболее важными и серьезными клиническими проблемами при хронической обструктивной болезни легких (ХОБЛ) являются наличие одышки и ограничений в выполнении привычных физических нагрузок (ФН) [1]. У больных ХОБЛ повышение частоты дыхания во время ФН приводит к сокращению времени выдоха и снижению эвакуации всей порции воздуха из альвеол, обуславливая дальнейшее увеличение воздушной ловушки [2]. Нарастание легочной гиперинфляции препятствует углублению дыхания или повышению нарастания дыхательного объема, что и является одной из основных причин одышки во время ФН. В свою очередь, одышка приводит к снижению физической работоспособности и ухудшению качества жизни (КЖ) пациентов [3].

Тиотропия бромид (Спирива $\left.{ }^{\circledR}\right)-$ антихолинергический препарат, имеющий фармакокинетическую селективность к $\mathrm{M}_{3}$ - и $\mathrm{M}_{1}$-рецепторам и обеспечивающий длительное бронхорасширяющее действие. Согласно международным и национальным рекомендациям, тиотропия бромид является одним из основных бронходилататоров, используемых в лечении ХОБЛ [1]. К настоящему времени опубликовано множество отечественных и зарубежных исследований эффективности этого препарата. Большинство из них отражают результаты недлительного лечения тиотропия бромидом (3-6 мес.) - преимущественно у больных ХОБЛ III-IV степени тяжести [4-6]. Лишь единичные работы содержат данные о вли- янии более длительной терапии тиотропия бромидом на толерантность к ФН и КЖ [7, 8].

Целью настоящего исследования было изучение динамики 6-минутного шагового теста (6-МШТ), характеризующего толерантность к физической нагрузке, и КЖ у больных ХОБЛ I-IV степени при терапии тиотропия бромидом в течение 1 года.

\section{Материалы и методы}

В исследовании участвовали 37 больных ХОБЛ в клинически стабильном состоянии, которым был впервые назначен тиотропия бромид в дозе 18 мкг (1 капсула тиотропия для ингаляций посредством ингалятора HandiHaler ${ }^{\circledR} 1$ раз в день. До включения в исследование все пациенты применяли ингаляции $\beta_{2}$-агонистов короткого действия по потребности. В зависимости от степени тяжести ХОБЛ они были разделены на 2 группы. В 1-ю группу вошли 17 больных в возрасте от 51 года до 73 лет с легкой и средней ХОБЛ (I-II степени), во 2-ю группу - 20 больных в возрасте 29-79 лет с тяжелой и крайне тяжелой ХОБЛ (III-IV степени). Это было открытое неконтролируемое несравнительное исследование. Наблюдение пациентов продолжалось в течение 12 мес. Контрольные точки оценки результатов лечения приходились на 3, 6 и 12 мес. Критерием включения в исследование было наличие ХОБЛ любой степени тяжести, диагноз которой ставился в соответствии 
c GOLD [1]. Критерии исключения были следующими: наличие бронхиальной астмы, нестабильное течение стенокардии, инфаркт миокарда в последние 3 мес., тяжелая сердечная недостаточность, нарушения ритма сердца, требующие назначения антиаритмических препаратов, отказ пациента участвовать в исследовании. Исследование было одобрено этическим комитетом Сибирского государственного медицинского университета. Характеристика больных представлена в табл. 1 .

В обеих группах преобладали мужчины. Пациенты 1-й группы имели достоверно более высокие показатели объема форсированного выдоха за 1-ю с $\left(\mathrm{OФB}_{1}\right)$, индекса Тиффно. Всем пациентам проводилось клиническое и инструментальное обследование, включающее спирографию (посредством спирографа MasterScreen, Erich Jaeger, Германия), рентгенографию органов грудной клетки, ЭКГ, ультразвуковое исследование сердца (с помощью эхокардиографа Aloca 3500, Япония).

Для определения толерантности к ФН использовали 6-МШТ, который в пульмонологической практике служит одним из методов оценки функционального статуса [9]. Он проводился внутри закрытого помещения, в прямом коридоре, удобном для ходьбы, длиной 36 м. Перед выполнением теста пациент отдыхал в течение 10 мин, измерялось артериальное давление, подсчитывались пульс и частота сердечных сокращений. Эти же параметры оценивались и после окончания ходьбы. До и после теста оценивали выраженность одышки по шкале Борга в баллах. Пациенты заранее знакомились с этой шкалой, что обеспечивало фиксацию даже минимальных ощущений, характеризующих одышку. Тест выполнялся 2 раза с интервалом $\geq 30$ мин, оценивались данные с лучшим показателем пройденной дистанции [9].

КЖ исследовали с помощью стандартизованного вопросника Госпиталя св. Георгия (St. George's Respiratory Questionnaire - SGRQ). Его официальная русскоязычная версия рекомендована НИИ пульмонологии ФМБА России. SGRQ включает 76 вопросов,

Таблица 1 Характеристика больных ХОБЛ

\begin{tabular}{|c|c|c|}
\hline Показатели & 1 -я группа, $n=17$ & 2-я группа, $n=20$ \\
\hline Возраст, лет (M $\pm m)$ & $63,0 \pm 8,1$ & $56,6 \pm 14,5$ \\
\hline Пол: м / ж & $12 / 5$ & $19 / 1$ \\
\hline $\begin{array}{l}\text { Интенсивность курения, } \\
\text { пачек / лет }\left(M e\left(Q_{1}-Q_{3}\right)\right)\end{array}$ & $\begin{array}{c}38,00 \\
(10,15-46,13)\end{array}$ & $\begin{array}{c}32,50 \\
(17,50-58,00)\end{array}$ \\
\hline $\begin{array}{l}\text { Индекс курящего } \\
\text { человека }\left(M e\left(Q_{1}-Q_{3}\right)\right)\end{array}$ & $\begin{array}{c}240,00 \\
(84,00-240,00)\end{array}$ & $\begin{array}{c}240,00 \\
(240,00-270,00)^{*}\end{array}$ \\
\hline $0 Ф B_{1}, л\left(M e\left(Q_{1}-Q_{3}\right)\right)$ & $1,89(1,69-2,35)$ & $1,11(0,95-1,36)^{*}$ \\
\hline $\begin{array}{l}\text { Индекс Тиффно, \% } \\
\left(M e\left(Q_{1}-Q_{3}\right)\right)\end{array}$ & $\begin{array}{c}54,09 \\
(49,78-59,57)\end{array}$ & $\begin{array}{c}36,18 \\
(30,21-40,66)^{*}\end{array}$ \\
\hline ИБС, $n$ (\%) & $2(11,8)$ & $1(5)$ \\
\hline ГБ, $n(\%)$ & $6(35,3)$ & $4(20)$ \\
\hline ИБС + ГБ, $n(\%)$ & $8(47,1)$ & $10(50)$ \\
\hline
\end{tabular}

Примечание: * - $p<0,01$ по сравнению с 1-й группой; ОФВ 1 - объем форсированного выдоха за 1-ю с; ИБС - ишемическая болезнь сердца, ГБ - гипертоническая болезнь, Me - медиана; $Q_{1}-Q_{3}-$ интерквартильный размах. в качестве оценочных параметров используются 4 домена: "Симптомы", "Активность", "Влияние", "Сумма". Оценка проводилась по 100-балльной шкале от 0 до 100: чем выше показатель баллов, тем ниже КЖ. В исследованиях, проводимых в динамике заболевания или при оценке эффективности различных лечебных программ, клинически значимыми считаются изменения той или иной шкалы минимум на 4 балла [10].

Статистическую обработку данных выполняли с помощью программ Microsoft Excel и Statistica 6.0. Проверку нормальности распределения количественных показателей проводили с использованием критерия Колмогорова-Смирнова. Для каждой выборки вычисляли следующие характеристики: $M-$ выборочное среднее, $m$ - ошибка среднего, $M e-$ медиана, $\mathrm{Q}_{1}-\mathrm{Q}_{3}-$ верхний и нижний квартили. Для определения достоверности различий между независимыми группами использовали непараметрический критерий Манна-Уитни. Статистическая достоверность величин до и после лечения определялась с помощью парного критерия Стьюдента. Различие между изучаемыми параметрами признавали достоверным при $p<0,05$.

\section{Результаты и обсуждение}

Не все включенные в исследование пациенты были обследованы на всех контрольных точках, т. к. часть из них досрочно выбыла из исследования по разным причинам. Из 17 пациентов 1-й группы через 3 мес. были обследованы 17 (100\%), через 6 мес. - 11 (65\%), через 12 мес. - 8 (47\%), а из 20 пациентов 2-й группы - $16(80 \%), 8(40 \%)$ и $13(65 \%)$ соответственно.

Анализ показал, что разброс индивидуальных величин 6-МШТ был достаточно большим - причем как при включении в исследование, так и на разных контрольных точках и при любой степени тяжести ХОБЛ. Исходно расстояние, пройденное больными 1-й группы, составило 0-668,3 м, 2-й группы 0-643,5 м. У большинства больных результаты 6-МШТ улучшились через 3 мес. (у 28 из 33 пациентов) и 6 мес. (у 17 из 19 человек). Через 12 мес. увеличение расстояния в 6-МШТ было зарегистрировано у 14 пациентов из 21.

При включении в исследование 2 пациента из 1-й группы и 1 больной - из 2-й не смогли до конца выполнить 6-МШТ. Причины были следующими: у 2 больных (ХОБЛ I-II степени) во время теста возникала загрудинная боль, при дополнительном исследовании у кардиолога у них было подтверждено наличие ИБС и назначена дополнительная терапия. Пациент из 2-й группы (ХОБЛ III степени) преждевременно прекратил тест из-за развития выраженной одышки. На последующих контрольных точках эти больные на фоне терапии тиотропия бромидидом смогли довести тест до конца с неплохими результатами. Через год у 1-го пациента дистанция 6-МШТ составила 214,5 м, у 2-го - 429 м; при выполнении теста у них не развился приступ стенокардии. У 3-го пациента результат теста достиг 536,2 м, при этом 
Таблица 2

Оценка одышки по икале Борга у больных ХОБЛ при выполнении 6-МШТ на фоне терапии тиотропия бромидом, Ме (Q1-Q3)

\begin{tabular}{|c|c|c|c|c|}
\hline \multirow[t]{2}{*}{ Визиты } & \multicolumn{2}{|c|}{ 1-я группа } & \multicolumn{2}{|c|}{ 2-я группа } \\
\hline & до теста & после теста & до теста & после теста \\
\hline Исходно & $0,00(0,00-1,00)$ & $0,50(0,50-3,00)$ & $0,50(0,00-1,00)$ & $3,00(2,00-6,00)$ \\
\hline Через 3 мес. & $0,00(0,00-0,50)$ & $0,50(0,00-1,00)$ & $0,00(0,00-1,00)$ & $3,00(2,00-4,00)$ \\
\hline Через 6 мес. & $0,00(0,00-0,00)$ & $0,50(0,00-1,00)$ & $0,50(0,00-0,50)$ & $3,00(1,50-3,00)^{*}$ \\
\hline Через 1 год & $0,00(0,00-1,00)$ & $1,00(1,00-2,00)$ & $0,50(0,00-1,00)$ & $3,00(1,00-7,00)$ \\
\hline
\end{tabular}

Примечание: * - $p<0,01$ по сравнению с исходными показателями.

выраженность одышки была менышей, чем при 1-м исследовании. Меньшее расстояние, по сравнению с исходными величинами 6-МШТ, через 12 мес. прошли 2 пациента из 1-й группы и 5 больных из 2-й группы. Снижение переносимости ФН у пациентов 1-й группы было обусловлено внелегочными причинами. Один больной перенес инсульт через полгода после включения в исследование, другой был прооперирован по поводу облитерирующего атеросклероза сосудов нижних конечностей (шунтирование). У 5 пациентов 2-й группы была крайне тяжелая ХОБЛ, причем у 4 из них имелось хроническое легочное сердце.

В среднем расстояние, пройденное больными 1-й группы на фоне терапии тиотропия бромидом, увеличилось через 3 мес. на 103,9 $\pm 30,0$ м $(p<0,003)$, через 6 мес. - на $113,7 \pm 42,0$ м $(p<0,01)$, а через 1 год на $46,7 \pm 51,2$ м $(p>0,05)$, как показано на рис. 1 . Во 2 -й группе дистанция увеличилась через 3 мес. лечения тиотропия бромидом на 91,3 $\pm 28,3$ м $(p<0,02)$, через 6 мес. - на $81,6 \pm 24,5$ м $(p>0,05)$ и через 1 год на 41,8 $\pm 60,6$ м ( $p>0,05$; рис. 2$)$.

У большинства больных переносимость ФН была ограничена одышкой. Степень одышки, выраженная в баллах, как до начала выполнения теста, так и после окончания ходьбы исходно и на всех контрольных точках была различной, но в среднем более выраженной во 2-й группе.

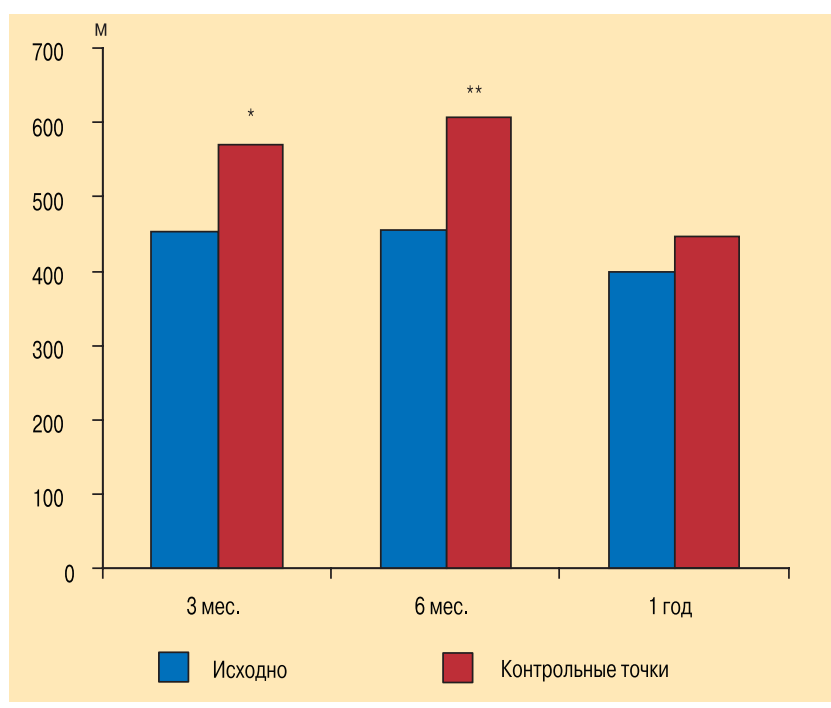

Рис. 1. Результаты 6-МШТ у больных 1-й группы Примечание: * $-p<0,003 ; * *-p<0,01$.
Несмотря на увеличение дистанции 6-МШТ в контрольных точках на фоне терапии тиотропия бромидом, у больных 1-й группы выраженность одышки при выполнении теста в среднем осталась на прежнем уровне. У пациентов 2-й группы интенсивность одышки достоверно снизилась через 6 мес. лечения $(p<0,01)$, а во время других визитов осталась на прежнем уровне, и ее выраженность не была большей, даже если больные проходили большее расстояние (табл. 2).

Результаты оценки КЖ представлены в табл. 3.

На фоне терапии тиотропия бромидом практически все больные 1-й группы чувствовали себя лучше и отмечали снижение частоты кашля, уменьшение объема мокроты и одышки, увеличение физической активности. Самым значительным снижение баллов было в домене "Симптомы". Так, через 3 мес. лечения оно составило 20,3 ( $p<0,0006)$, через 6 мес. $-18,2(p<0,02)$, через 1 год $-12,7$ балла $(p>$ $0,05)$. Домен "Сумма" также отразил изменения в сторону улучшения самочувствия исследуемых: через 3 мес. сумма баллов уменьшилась на 6,7 ( $p<0,003)$, через 6 мес. - на 8,0 ( $p<0,02)$, через 1 год - на 0,8 балла $(p>0,05)$. В домене "Активность" через 3 мес. лечения зарегистрировано снижение на 5,6 балла, через 6 мес. - на 5,8 балла. В домене "Влияние" сумма балов уменьшилась через 3 мес. на 5,3 балла, через 6 мес. - на 5,8 балла, через 1 год терапии тио-

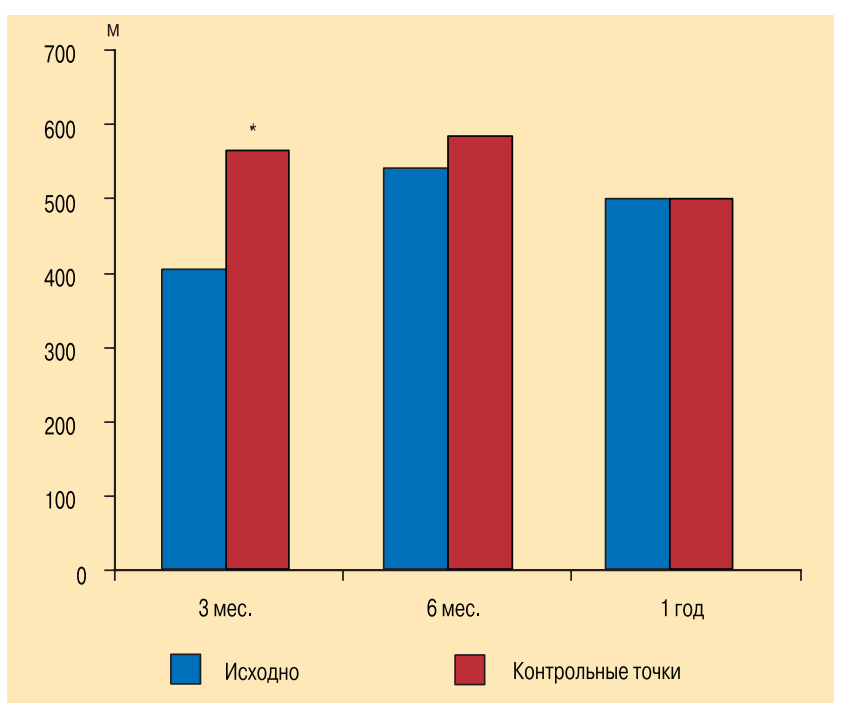

Рис. 2. Результаты 6-МШТ у больных 2-й группы Примечание: ${ }^{*}-p<0,02$. 
Сумма баллов SGRQ у больных ХОБЛ на фоне терапии тиотропия бромидом, Ме $\left(Q_{1}-Q_{3}\right)$

\begin{tabular}{|c|c|c|c|c|c|cc|c|}
\hline \multirow{2}{*}{ Домены } & \multicolumn{9}{|c|}{1 -я группа } & \multicolumn{4}{|c}{ 2-я группа } \\
\cline { 2 - 10 } & исходно & через 3 мес. & через 6 мес. & через 1 год & исходно & через 3 мес. & через 6 мес. & через 1 год \\
"Сумма" & 31,08 & 24,35 & 23,12 & 30,25 & 38,85 & 34,36 & 31,14 & 39,43 \\
& $(22,87-35,31)$ & $(18,06-31,27)^{*}$ & $(19,78-26,28)^{*}$ & $(24,86-35,13)$ & $(34,32-48,88)$ & $(27,10-42,51)^{*}$ & $(28,49-37,08)^{*}$ & $(31,89-47,92)$ \\
"Активность" & 30,08 & 24,62 & 24,30 & 33,88 & 43,72 & 43,07 & 43,10 & 44,29 \\
& $(23,52-37,21)$ & $(24,24-36,93)$ & $(18,35-30,13)$ & $(23,34-36,87)$ & $(30,75-59,82)$ & $(34,12-53,31)$ & $(39,69-47,07)$ & $(42,12-56,43)$ \\
"Симптомы" & 62,47 & 42,20 & 44,31 & 49,80 & 79,72 & 51,88 & 39,48 & 55,32 \\
& $(44,49-76,60)$ & $(26,30-52,52)^{*}$ & $(30,97-47,09)^{*}$ & $(44,70-56,64)$ & $(62,18-83,82)$ & $(40,73-69,38)^{*}$ & $(21,54-63,48)^{*}$ & $(41,19-61,84)$ \\
"Влияние" & 21,91 & 16,64 & 16,53 & 17,30 & 27,56 & 22,86 & 23,13 & 26,90 \\
& $(16,71-23,56)$ & $(12,72-24,02)$ & $(12,73-19,10)$ & $(14,99-26,70)$ & $(19,00-35,26)$ & $(18,42-32,63)$ & $(19,37-27,21)$ & $(22,80-34,89)$
\end{tabular}

Примечание: * - p<0,01 по сравнению с исходными показателями.

тропия бромидом - на 4,6 балла. В доменах "Активность" и "Влияние" изменения были статистически незначимыми, но показатели снизились на $>4$ балла, что считается клинически значимым [10]. Такие же результаты были получены через 1 год лечения по доменам "Симптомы" и "Сумма". Лишь по домену "Активность" через 1 год терапии не отмечено клинически значимого улучшения по сравнению с исходной суммой баллов. У пациентов 2-й группы уменьшилась выраженность симптомов заболевания (домен "Симптомы"): через 3 мес. количество баллов уменьшилось на 27,8 ( $p<0,009)$, через 6 мес. - на 40,2 $(p<0,01)$, через 1 год - на 24,4 $(p>0,05)$. По домену "Сумма" отмечено снижение через 3 мес. на 4,9 $(p<0,001)$, через 6 мес. - на 7,7 балла $(p>0,05)$. В домене "Влияние" через 3 мес. зарегистрировано уменьшение суммы на 4,7 балла, через 6 мес. - на 4,4 балла. Таким образом, по доменам "Влияние" (через 3 и 6 мес.), "Симптомы" (во время всех контрольных визитов) и "Сумма" (через 3 и 6 мес.) во 2-й группе имело место клинически значимое улучшение. Только по шкале "Активность" клинически значимого улучшения не было ни в одной контрольной точке.

До недавнего времени при оценке эффективности терапии ХОБЛ в конечных точках ориентировались на параметры легочной функции. Однако ОФВ 1 как показатель степени тяжести бронхиальной обструкции не соответствует степени выраженности клинических признаков ХОБЛ, нарушению толерантности к ФН и КЖ, связанных со здоровьем больных ХОБЛ [11]. Исследование только функции внешнего дыхания не позволяет оценить степень дезадаптации. В клинической практике 6-МШТ широко используется среди пациентов с ХОБЛ, и дистанция, пройденная в этом тесте, по мнению многих исследователей, адекватно отражает способность больного к выполнению ФН [12, 13]. Как уже было отмечено, в настоящем исследовании расстояние в 6-МШТ заметно варьировалось даже в пределах одной и той же стадии патологии, классифицируемой только на основании ОФВ 1 . Это свидетельствует о несоответствии выраженности клинических признаков ХОБЛ и функциональных возможностей пациента степени тяжести ХОБЛ, определяемой по ОФВ 1 [14].

Следует иметь в виду, что тест 6-МШТ - саморегулируемый, что позволяет больному выбирать темп ходьбы и отдыхать во время его выполнения [13]. Поэтому невыполнение 6-МШТ или низкие его показатели могут быть связаны с поведенческим компонентом, выражающимся в том, что пациенты избирательно уменьшают свою физическую активность [15]. Зависимость активности не только от физической способности, но и от психосоциальных факторов и факторов окружающей среды отмечают S.E.Turner et al. [13].

Тревожность и низкая мотивация также вносят вклад в плохую переносимость ФН. Как показал анализ, все эти обстоятельства имели место и в настоящем исследовании. В частности, они повлияли на результаты в 3-й контрольной точке, которая у части больных пришлась на холодное время года. Кроме того, ограничение физической активности и способности выполнять ФН связано с наличием ассоциированных с ХОБЛ заболеваний, которые имелись у многих пациентов. Тем не менее у большинства из них толерантность к ФН улучшилась на фоне терапии тиотропия бромидом: в обеих группах через 3 и 6 мес. значимо увеличилось расстояние, пройденное при выполнении 6-МШТ. Через год терапии также было зарегистрировано увеличение дистанции при проведении теста, но оно не было достоверным. Вероятно, для дальнейшего улучшения функциональных возможностей пациентов требуется расширение лечебных программ. Например, в нескольких исследованиях показано, что физическая реабилитация улучшает параметры физической активности и психоэмоционального статуса у больных ХОБЛ [7].

В показателе КЖ интегрирована способность пациента адаптироваться к проявлениям заболевания. На фоне терапии тиотропия бромидом сумма баллов уменьшилась на $\geq 4$ в большинстве доменов - при оценке эффективности различных лечебных программ такой показатель свидетельствует о клинически значимом улучшении КЖ.

\section{Заключение}

Таким образом, настоящее исследование показало, что длительная терапия тиотропия бромидом позволяет улучшить переносимость ФН и повысить КЖ у пациентов с любой стадией ХОБЛ. 


\section{Литература}

1. Чучалин А.Г. (ред.). Глобальная стратегия диагностики, лечения и профилактики хронической обструктивной болезни легких: Пер. с англ. М.: Изд. дом "Атмосфера"; 2007.

2. Celli B.R., MacNee W. ATS / ERS Task Force. Standards for the diagnosis and treatment of patients with COPD: a summary of the ATS / ERS position paper. Eur. Respir. J. 2004; 23: 932-946.

3. Авдеев С.Н. Возможна ли модификация заболевания при ХОБЛ? Роль бронходилататора длительного действия тиотропия бромида. Consilium Medicum 2008; 10 (3): $57-64$.

4. Casaburi R., Kukafka D., Cooper C.B. et al. Improvement in exercise tolerance with the combination of tiotropium and pulmonary rehabilitation in patients with COPD. Chest 2005; 127 (3): 809-817.

5. Celli B.R., Zu Wallack R., Wang S. et al. Improvements in resting inspiratory capacity and hyperinflation with tiotropium in COPD with increased static lung volumes. Chest 2003; 124: 1743-1748.

6. O'Donnell D.E., Fluge T., Gercen F. et al. Effects of tiotropium on lung hyperinflation, dyspnea and exercise tolerance in COPD. Eur. Respir. J. 2004; 23: 832-840.

7. Игнатьев В.А., Титова О.Н., Дидур М.Д. и др. Влияние тиотропия бромида на эффективность легочной реабилитации у больных хронической обструктивной болезнью легких. Пульмонология 2007; 1: 88-94.

8. Комлев А.Д., Кузяев А.И., Кузенкова В.Е. и др. Опыт применения тиотропия бромида (Спирива) в течение 12 месяцев у больных хронической обструктивной болезнью легких. Пульмонология 2006; 3: 107-113.
9. Crapo R.O., Casaburi R., Coates A.L. et al. ATS Statement: Guidelines for the Six-Minute Walk Test. Am. J. Respir. Crit. Care Med. 2002. 166: 111-117. Электрон. ресурс режим доступа www.atsjournals.org

10. Чучалин А.Г. Качество жизни у больных бронхиальной астмой и хронической обструктивной болезнью легких. М.: Атмосфера; 2004.

11. Ambrosino N. Dyspnoea and its measurement. Breath 2004; 1 (2): 101-107.

12. Casanova C., Cote C.G., Marin J.M. et al. The 6-minute walking distance: long-term follow up in patients with COPD. Eur. Respir. J. 2007; 29: 535-540.

13. O'Donnell D.E. Lung mechanics in COPD: the role of tiotropium. Eur. Respir. Rev. 2004; 13 (89): 40-44.

14. Turner S.E., Eastwood P.R., Cecins N.M. et al. Physiologic responses to incremental and self-paced exercise in COPD. Chest 2004; 126: 766-773.

15. Watz H., Waschki B., Meyer T. et al. Physical activity in patients with COPD. Eur. Respir. J. 2009; 33: 262-272.

\section{Информация об авторах}

Волкова Людмила Ивановна - д. М. н., проф., зав. кафедрой внутренних болезней педиатрического факультета СибГМУ; тел.: (3822) 41-98-44; e-mail: luda@mail.tomsknet.ru

Тимофеева Александра Васильевна - аспирант кафедры внутренних болезней педиатрического факультета СибГМУ; тел.: (3822) 41-98-44; e-mail: tav_76@inbox.ru

Смолина Елена Станиславовна - врач МКлПМУ "Городская больница № 3"; тел.: (3822) 41-98-77; e-mail: smolina-elena@sibmail.ru

Аминова Зульфия Рашидовна - врач МКлПМУ "Городская больница № 3"; тел.: (3822) 41-98-77; e-mail: aminova@vtomske.ru

Поступила 09.04.10 () Коллектив авторов, 2010 удк 616.24-036.12-085.23 